Corrigendum

\title{
Corrigendum to "Wearable Passive E-Textile UHF RFID Tag Based on a Slotted Patch Antenna with Sewn Ground and Microchip Interconnections"
}

\author{
Johanna Virkki $\mathbb{D}^{\mathrm{D}},{ }^{1}$ Zhigang Wei, ${ }^{2}$ Aruhan Liu, ${ }^{2}$ Leena Ukkonen $\mathbb{D}^{1},{ }^{1}$ and Toni Björninen $\mathbb{D}^{1}$ \\ ${ }^{1}$ Department of Electronics and Communications Engineering, Tampere University of Technology, Tampere, Finland \\ ${ }^{2}$ Department of Electronic Engineering, City University of Hong Kong, Hong Kong, Hong Kong \\ Correspondence should be addressed to Johanna Virkki; johanna.virkki@tut.fi \\ Received 22 July 2020; Accepted 23 July 2020; Published 27 September 2020 \\ Copyright () 2020 Johanna Virkki et al. This is an open access article distributed under the Creative Commons Attribution \\ License, which permits unrestricted use, distribution, and reproduction in any medium, provided the original work is \\ properly cited.
}

In the article titled "Wearable Passive E-Textile UHF RFID Tag Based on a Slotted Patch Antenna with Sewn Ground and Microchip Interconnections" [1], the Acknowledgments section should be corrected as follows:

\section{Acknowledgments}

This research work was supported by the European Commission AdvIOT IRSES Project, Academy of Finland (decision number 294534), Jane and Aatos Erkko Foundation, and TEKES.

\section{References}

[1] J. Virkki, Z. Wei, A. Liu, L. Ukkonen, and T. Björninen, "Wearable passive E-textile UHF RFID tag based on a slotted patch antenna with sewn ground and microchip interconnections," International Journal of Antennas and Propagation, vol. 2017, Article ID 3476017, 8 pages, 2017. 